\title{
Significance of Nursing Students' Experiences as Health Volunteers in Communities: A Qualitative Study
}

\section{Chisato Kimura* and Junko Masuya}

Tokyo Metropolitan University, Graduate School of Human Health Sciences, Department of Nursing Sciences 7-2-10 Higashiogu, Arakawa-ku, Tokyo, 116-8551, Japan

\section{Abstract}

Background: The latter half of the 1990s witnessed the introduction of volunteer activities in primary and secondary school; such efforts were reportedly also taking place in nursing schools. Limited study has focused on the knowledge gained by nursing students through their experience as health volunteers in different fields within the community and the significance of this knowledge. This study investigated the knowledge gained from and the significance of the experiences of nursing students who worked as health volunteers for child rearing women, people with early-onset dementia, and their families.

Methods: The study employed a qualitative research design, conducting in-depth interviews. Content analysis was applied to analyze data derived from the statements of 10 nursing university graduates who served as volunteers.

Results: Three themes consisting of 6 categories and 13 subcategories were correlated with the knowledge that the nursing students gained through their experiences as health volunteers. The three themes were (1) understanding the clients, (2) understanding the basics of healthcare practices, and (3) envisioning the future.

Conclusions: The nursing students learned the value of understanding their clients' characteristics, including their clients' family members, and gave care through their experiences accordingly; further, this gave them insight into their own profession and helped them see themselves in the future as nurses and productive members of society/the community. The results of this study will be used as basic materials for linking and integrating regional services and programs offered by university students into curricula through various ways.

\section{Introduction}

The necessary characteristics of volunteer work are that it should be voluntary, nonprofit, and public; the additional characteristics are that it be creative, pioneering, and reciprocal [1]. Since research and lectures in the latter half of the 1990s began focusing on the topic of volunteering, volunteer programs have been introduced into the education system, and their effectiveness in training those who will be the future support of a democratic society in the future has been recognized. There have been reports of practical examples of volunteer activities being used in medical, pharmaceutical, and nursing education as well [2-5]. In recent years, "service learning," with clearly defined educational goals and methods, has been introduced in educational programs; information and knowledge that can be used in their practical application have been indicated $[7,8]$.

Service programs [6] that include volunteer work are based on two indices; the beneficiaries of the activity and the focus of the activities. They are broadly divided into "volunteerism," "community service," "service learning," "internship," and "field education" based on these two indices [9]. Volunteerism mainly aims to provide a service, and the main beneficiaries are those who are provided the service. Even though students derive benefit and knowledge from the volunteer activity, these are not among the intended effects of volunteer work. On the other hand, service learning provides benefits to both the service providers and recipients. This means that focus is placed on learning and service in such a way that the service is integrated into the class. This allows the students to apply the theory and technical skills learned in the class while providing the service. The services required by the community and learning by the students being equal goals in this model are indicated to be the main difference from other programs. programs [11]. (Ext 480); E-mail: ckimura@tmu.ac.jp original author and source are credited.

\section{Publication History:}

Received: February 11, 2017

Accepted: April 06, 2017

Published: April 08, 2017

\section{Keywords:}

Child rearing women, Learning, People with early-onset dementia, Service, University advocated the experiential learning theory, wherein "knowledge is created through the transformation of experience. Knowledge results from the combination of grasping and transforming experience." This process is a type of cyclical learning, based on (1) concrete experience, (2) reflective observation, (3) abstract conceptualization, and (4) active experimentation. It is applied at the university level in the development of medical education programs, including nursing

Because incorporating service programs in nursing curriculum courses creates workload-related problems such as time, effort, responsibilities toward clients, and partnerships between students, instructors, and local communities [12,13], there are still very few nursing departments that have designated service learning as a part of formal education. Though differences in organizational philosophy and traditions remain, volunteering has been adopted in a variety of forms as a service program [14]. It has been reported that students and local residents, who are the beneficiaries, benefit from volunteering [15], but limited information is available.

"Corresponding Author: Chisato Kimura, Tokyo Metropolitan University, Graduate School of Human Health Sciences, Department of Nursing Sciences 7-2-10 Higashiogu, Arakawa-ku, Tokyo, 116-8551, Japan, Tel: +81-3-3819-1211

Citation: Kimura C, Masuya J (2017) Significance of Nursing Students' Experiences as Health Volunteers in Communities: A Qualitative Study. Int J Nurs Clin Pract 4: 232. doi: https://doi.org/10.15344/2394-4978/2017/232

Copyright: (c) 2017 Kimura et al. This is an open-access article distributed under the terms of the Creative Commons Attribution License, which permits unrestricted use, distribution, and reproduction in any medium, provided the 
This study aimed to elucidate the knowledge gained by university students who participated in two different types of volunteer activities; providing support to child rearing women and their families, and providing support to people with early-onset dementia and their families. This included characteristics of service learning, such as service experience through cooperation with the community, civic education, correlation with a curriculum, and systematic reflection, even though these activities were not the types of systematic programs normally used in service learning. After reviewing the experience of the nursing students, the significance of the knowledge they gained from volunteering was explored.

Findings from this study would suggest how nursing students connect learning through experience of community service for clients at different stages of life with learning in the classroom, and would serve as useful information for nursing faculties, when supporting students in various service programs.

\section{Objective}

This study mainly described the learning gained from and the significance of the experiences of nursing students or graduates who provided services as health volunteers to child rearing women and their families as well as to early-onset dementia patients and their families.

\section{Methods}

\section{Design}

Qualitative explorative approach using content analysis.

\section{Participants}

A total of 10 nursing university graduates who provided assistance as volunteers to women raising children and their families as well as to people with early-onset dementia and their families.

\section{Data collection and analysis}

Data collection: The participants were recruited through purposive sampling via the heads of volunteer groups or volunteer coordinators in Tokyo. Subsequently, one-on-one semi-structured interviews approximately 1 hour in length were given. The interviews were conducted at the university of authors. Interviews were recorded and transcribed. Interview guide: The participants were asked: (1) their reason for volunteering and the sequence of events leading to their participation in the volunteer activity, (2) the preparations they undertook prior to participating in the volunteer activity, (3) their experience participating in the volunteer activity as well as anything that particularly impressed them, their thoughts and actions while participating in the volunteer activity, and (4) the knowledge gained through the volunteer activities and the significance of the experience.

Data analysis: Qualitative inductive analysis was performed according to the following procedure: (1) Individual analysis: (a) transcripts were carefully read, and statements that revealed the knowledge and significance gained from their volunteer experience were identified, and (b) sentences with similar meanings were categorized, and codes that indicated the meanings of the categorized sentences were generated; (2) Overall analysis: (a) all codes were thoroughly read, similar codes were compared and organized, and subcategories were generated, and (b) by continuing this process, the data was condensed; and (3) Confirming the authenticity and validity of the results: (a) the process of this study was supervised by a professional qualitative researcher, and (b) it was thus verified that the categories and subcategories accurately reflected participants' views.

\section{Rigor}

The rigor of this study was ensured by establishing its credibility, dependability; confirmability, transferability, and authenticity [16]. Specifically, two participants conducted member checks for the subthemes and themes (credibility); we reviewed studies related to experiences and knowledge derived from volunteer work in areas other than healthcare and compared the results of those studies with the results of this study. This was done to provide descriptive data for readers to assess the applicability of the data in different contexts (transferability). Two researchers experienced in the field of qualitative research conducted a thorough survey of all processes related to data analysis (dependability).

Audit trails to decide all the methodological procedures for data analysis including the drafts of the transcripts and the records of reviews and critiques of previous research were filed (conformability). The researchers reread the transcripts, considered possible themes, and quoted representative participant statements found in the subcategories. We then presented the significant meaningful sentences as descriptive data (authenticity).

\section{Ethical Considerations}

This study was approved by the Institutional Review Board of Tokyo Metropolitan University. We instituted the following procedures to protect the participants from adverse events: (1) Prior to the interviews, the participants were provided both oral and written explanations about the objective of the study and its procedures; moreover, oral and written consent was obtained from all participants; (2) The participants were explained that participation in the study was based on their free will; further, we explained the methods that would be employed to protect their confidentiality and privacy, their right to refuse to answer any questions, and to withdraw from the study at any time would be guaranteed. (3) The participants were informed that the results of the study may be published.

\section{Results}

\section{Background of the participants}

\section{Characteristics of the participants ( Table 1)}

\begin{tabular}{|c|c|c|c|c|}
\hline Participants & Occupation & Age & $\begin{array}{c}\text { Previous } \\
\text { volunteer } \\
\text { experiance }\end{array}$ & $\begin{array}{c}\text { Duration of } \\
\text { voluntering } \\
\text { (Month) }\end{array}$ \\
\hline A & Nurse & 37 & No & 36 \\
\hline B & Nurse & 23 & No & 24 \\
\hline C & Nurse & 23 & No & 24 \\
\hline D & Nurse & 28 & No & 12 \\
\hline E & Nurse & 23 & No & 12 \\
\hline F & Midwife & 24 & Yes & 24 \\
\hline G & Midwife & 24 & No & 7 \\
\hline H & Midwife & 24 & No & 24 \\
\hline I & Midwife & 25 & No & 24 \\
\hline J & Midwife & 24 & Yes & 24 \\
\hline
\end{tabular}

Table 1: Background characteristics of participants. 
Citation: Kimura C, Masuya J (2017) Significance of Nursing Students' Experiences as Health Volunteers in Communities: A Qualitative Study. Int J Nurs Clin Pract 4: 232. doi: https://doi.org/10.15344/2394-4978/2017/232

Page 3 of 7

The study subjects were 10 nursing university graduates (five midwives and five nurses). All subjects were female. The mean age was 25.5 (range 23-37) years. The mean duration of their volunteer activities was 21.1 (7-36) months. The main reasons given by the participants for becoming involved in volunteer activities, mostly related to their future job, were being invited/ encouraged by upperclassmen, friends, teachers, or university announcements, and being an interest in volunteer activities. Less common motivations included having a person with similar needs in their family/relative and wanting to gain experience in society.

\section{Service program contents and the process of applying those contents for support}

Elder support volunteering consisted of local community service performed once per month for people with early-onset dementia and their family-member caregivers. Each activity was attended by approximately 10 groups of people with early-onset dementia and their family-member caregivers, as well as approximately 10 undergraduate and postgraduate students, local community volunteers, and university faculty who acted as support. The outings were creative activities, sports, and mountain climbing/hiking. The outings were planned and conducted by volunteers to provide clients and families a pleasant experience, and adjusted to the needs of each individual. These activities were designed to allow people with earlyonset dementia and their family-member caregivers to share enjoyable experiences. They were also designed to provide people with earlyonset dementia senses of accomplishment and capability, and provide the family caregivers opportunities to share information and interact, and ensure some respite. The child rearing support volunteering consisted of providing support to mothers who had given birth within the past six months, as well as to the family members of these mothers, through childrearing and housework support during home visits. The child rearing support volunteer members were students, local community volunteers, university faculty, and social welfare council workers. The child rearing volunteer organization received financial support from the local government. The university student volunteers supported mothers emotionally, assisted with housework and baby care, and played with older children for two-hour periods. Reflection meetings, consisting of case conferences, care coordination, and team organization, were held monthly.

When providing support, the participants in this study were confused and reported that they "did not know what to do at first" and "just watched what was happening." But, they then "used what other supporters were doing as an example" and, through "trial and error," they gradually moved on to the ability to "think and act on their own" and "act with purpose," until they were finally able to "apply knowledge and techniques they acquired to daily practice."

\section{Significance of nursing student volunteers' experiences and their learning ( Table 2)}

Each theme related to the learning derived through volunteering experiences of the nursing student is given a number. The categories appear in parentheses and the subcategories are italicized.

\section{Understanding the clients}

\section{Understanding the characteristics of the clients}

\section{Comparison with learning gained in the classroom}

The nursing student volunteers reviewed their class materials and notes regarding the physical, psychological, and social characteristics

\begin{tabular}{|c|c|c|}
\hline Theme & Category & Sub-Category \\
\hline \multirow{6}{*}{$\begin{array}{l}\text { Understanding } \\
\text { the clients }\end{array}$} & \multirow[t]{3}{*}{$\begin{array}{l}\text { Understanding the } \\
\text { characteristics of the } \\
\text { clients }\end{array}$} & $\begin{array}{l}\text { Comparision with } \\
\text { learnig gained in the } \\
\text { class room }\end{array}$ \\
\hline & & Understanding diversity \\
\hline & & $\begin{array}{l}\text { Understanding } \\
\text { Individuality }\end{array}$ \\
\hline & \multirow{3}{*}{$\begin{array}{l}\text { Searching for } \\
\text { fundamental rules for } \\
\text { the care required by } \\
\text { the clients }\end{array}$} & $\begin{array}{l}\text { The feeling and attitude } \\
\text { of respect }\end{array}$ \\
\hline & & $\begin{array}{l}\text { Avoiding risks and } \\
\text { ensuring safety }\end{array}$ \\
\hline & & $\begin{array}{l}\text { Including the clients' } \\
\text { family members within } \\
\text { the scope of care }\end{array}$ \\
\hline \multirow{6}{*}{$\begin{array}{l}\text { Understanding } \\
\text { the basics of } \\
\text { healtcare prctices }\end{array}$} & \multirow{3}{*}{$\begin{array}{l}\text { The essentials of care } \\
\text { underpinning nursing } \\
\text { prctices }\end{array}$} & Careful observations \\
\hline & & $\begin{array}{l}\text { Establishing } \\
\text { rapport through } \\
\text { communication }\end{array}$ \\
\hline & & Providing nursing skills \\
\hline & \multirow{3}{*}{$\begin{array}{l}\text { The importance of } \\
\text { cooperartion and } \\
\text { continuity }\end{array}$} & $\begin{array}{l}\text { Intra-organizational } \\
\text { communication }\end{array}$ \\
\hline & & $\begin{array}{l}\text { Cooperation between } \\
\text { non-specialists and } \\
\text { specialists }\end{array}$ \\
\hline & & Continual support \\
\hline \multirow[t]{4}{*}{$\begin{array}{l}\text { Envisioning the } \\
\text { future }\end{array}$} & \multirow[t]{2}{*}{$\begin{array}{l}\text { A vision of work } \\
\text { and life }\end{array}$} & $\begin{array}{l}\text { Increasing interest in } \\
\text { and selecting a major }\end{array}$ \\
\hline & & $\begin{array}{l}\text { Envisioning oneself at } \\
\text { all stage of life }\end{array}$ \\
\hline & \multirow[t]{2}{*}{$\begin{array}{l}\text { Increasing interest in } \\
\text { volunteering }\end{array}$} & $\begin{array}{l}\text { Gaining a renewed } \\
\text { understanding of the } \\
\text { social significance of } \\
\text { volunteer activities }\end{array}$ \\
\hline & & $\begin{array}{l}\text { Interest in organizing } \\
\text { volunteer work }\end{array}$ \\
\hline
\end{tabular}

Table 2: Singnificance of nursing students volunteers' experiances and their learning.

of the clients so that they could link learning in the class program to the actual circumstances of the clients they were supporting.

"In situations where I lacked the necessary knowledge, I reviewed the class materials and borrowed books from the library. I was also asked questions, and I provided support after reviewing my textbooks and considering related texts."

\section{Understanding diversity}

The nursing student volunteers gained an understanding of the diversity of the behavioral and cognitive characteristics of the clients, as well as differences in their individual circumstances. Even though the students experienced confusion and surprise, their perspective was broadened.

"While some clients seemed to be so normal that I doubted they had dementia, others were unable to hold conversations. As a result, I learned that each person had different physical and cognitive abilities, as well as the fact that even the same person can display different behaviors on different days." 
Citation: Kimura C, Masuya J (2017) Significance of Nursing Students' Experiences as Health Volunteers in Communities: A Qualitative Study. Int J Nurs Clin Pract 4: 232. doi: https://doi.org/10.15344/2394-4978/2017/232

Page 4 of 7

\section{Understanding individuality}

The nursing student volunteers gained an understanding of each individual by observing behavior and cognition, differences in family background, and each person's individual history, interests, and support needs, and the students adjusted the types of support that they provided accordingly.

"Since people with dementia yet have their experiences and all that they have accumulated throughout their lives, I learned that I can deal with clients by using their remaining skills, as well as the work, pleasures, and interests that are related to their experiences."

\section{Searching for fundamental rules for the care required by clients}

\section{The feeling and attitude of respect}

The nursing student volunteers realized the difficulty of dealing with clients through the process of repeatedly providing services to them, and they gained respect for client's personality, individuality, and personal history as a fundamental rule".

"I provided service to the clients while carefully listening to narratives about their experiences without hurting their pride."

\section{Avoiding risks and ensuring safety}

Participants valued safety for clients and their family without any accidents, and considered predicting high risk conditions to prepare safety measures as more important.

"The situation in which a mother may have been suffering from postpartum depression was potentially dangerous made me worry about what would happen to the child if the mother suffers from depression, so I discussed this situation with a local volunteer coordinator."

\section{Including the clients' family members within the scope of care}

In addition to understanding the experiences and sources of clients' family member's suffering, the participants also assessed the relationships within the client's family, thought about ways of ensuring the well-being and empowerment of the family members close to the client, and determined if and how specialists could be of help.

"I recognized people with early-onset dementia and their families needed support from specialists who understood the sources of suffering, the level of exhaustion, their family relationships, and who provided a place to relax and formed friendships."

\section{Understanding the basics of healthcare practices}

\section{The essentials of care underpinning nursing practices}

\section{Careful observations}

The participants said that sensitive observations allowed them to think about the need to infer both verbal and nonverbal messages, and allow to plan care by assessing the stages of symptoms and development.

"I realized that it is important not only to pay attention to words but also to sense the feelings behind the words by observing facial expressions and gestures. Careful observation allowed me to understand better whether the client and family member were progressing normally, whether they were relaxed in their circumstances, or whether their condition was deteriorating."

\section{Establishing rapport through communication}

The participants were confused and experienced a feeling of inadequacy as they were unaware about didn't know how to form relationships at first, but as they endeavored to continue communicating, they began to enjoy the process of forming relationships and were happy when they succeeded in gaining the trust of the clients.

"At first, I was nervous and confused, but after several attempts, I noticed that the stiff looks on the faces of the clients began to soften and, as we became familiar through relaxed conversation, I began to enjoy myself more."

\section{Providing nursing skills}

The participants endeavored to promote client assurance and comfort and reduced their burden by applying nursing skills such as "remaining close", "watchful care", "sharing enjoyment", and "nurturing care."

"At first, I watched the recipient to determine how they were doing, and then after discussing the issue, I attempted a variety of methods, including just staying by their side on some days, engaging in enjoyable conversation, doing things I was asked to help [with], and providing care on other days."

\section{The importance of cooperation and continuity}

\section{Intra-organizational communication}

As members and leaders of volunteer organizations, the participants shared information about clients including high-risk cases appropriately based on multi-generational communication with peers and many levels of coworkers while receiving assurance and a variety of viewpoints.

"I felt I was unable to handle the case of postpartum depression because I'm a student, so I consulted the volunteer coordinator. We then reported the case at the case conference held at the monthly meeting, which led to an opportunity to discuss methods for improving the support system."

\section{Cooperation between non-specialists and specialists}

At follow-ups and case conferences regarding high-risk cases, the participants observed volunteer coordinators report to and consult with local specialists such as public health nurses, midwives and social workers, and the student volunteers learned methods of establishing and reinforcing a community support system for the clients.

"Because postpartum depression can become serious if allowed to continue, this problem was too important for a student to handle, so I had the client consult with a volunteer coordinator, who then reported the information to the local municipality, and a public health nurse took charge of that case."

\section{Continual support}

The participants continually dealt with high-risk clients such as women with postpartum depression and learned about the progress and developmental changes of clients that cannot be ascertained at any single point in time and learned to adapt to these changes. 
Citation: Kimura C, Masuya J (2017) Significance of Nursing Students' Experiences as Health Volunteers in Communities: A Qualitative Study. Int J Nurs Clin Pract 4: 232. doi: https://doi.org/10.15344/2394-4978/2017/232

Page 5 of 7

"I learned that once I go to work at a hospital, it is important to provide continuous care from pregnancy to postpartum to allow mothers to enjoy the child-rearing experiences; moreover, it is necessary to continually follow up with mothers and children after being discharged from the hospital."

\section{Envisioning the future}

\section{A vision of work and life}

\section{Increasing interest in and selecting a major}

The participants found enjoyment and a sense of purpose in providing services to the clients, gained interest in specialization as a result of their experience as volunteers, and, in some cases, even found that the experience assisted in guiding them toward their future profession.

"Being in charge of a particular case while volunteering gave me an opportunity to become interested in my specialty. The experience of volunteering was useful in helping me to plan care for clients and to provide health education."

\section{Envisioning oneself at all stages of life}

The participants imagined themselves at the childrearing and/or the senior/old stages as well as the situation their family would be in when it included an elderly member for anticipating what they would be like at all stages of life.

"I think I will have a variety of problems related to child-rearing once I have a baby. When that happens, I would like to utilize a service like this one. I also want to do something useful or helpful for others once I reach middle and old age."

\section{Increasing interest in volunteering}

Gaining a renewed understanding of the social significance of volunteer activities

The participants gained an interest in instilling a tradition of volunteerism in future generations through their own activities and in encouraging the next generation of volunteers; further, they gained a renewed understanding of the meaning of volunteer activities to university students, as well as the significance of the activities themselves by observing and hearing how other volunteers are assessed in society.

"I was greatly assisted by the fact that the activity was praised as an important effort in the community. I also think it is great that those who received support want to support others in some day."

\section{Interest in organizing volunteer work}

The participants gained interest in the growth, development, and system of volunteer organizations and formed an image of how they could create such an organization on their own and how to support such organizations.

"I was able to closely observe the growth and activities of volunteer groups, which provided an image of how to create organizations and volunteer groups."

\section{Discussion}

The motivation and experience of volunteering by nursing students

All the participants began healthcare volunteering during adolescence. Their reasons for volunteering were recommendations from others or the organization they belonged to, the relationship to their future employment, and an interest in volunteering. This indicates that they discovered meaning in social interactions with others and in conducting activities that were important to the community. They wanted to participate in volunteer work as a method of making connections with the community, and gaining important life experiences, and recognized such activities as valuable and important. These findings appear to support the results of previous studies $[17,18]$.

All participants began volunteering work in their second year of study or later; so they may have learned the importance of communication with and empathy toward others as part of their basic nursing skills training during their first year [19]. Empathy is one of the personality traits that plays an important role in one's decision to become a health volunteer engaged in the community services [20]. So it is possible participants in the present study had already recognized the importance of empathy, and this may have affected the process of deciding to begin and continue volunteering.

Nursing students went from not knowing what to do, to being sociable through their experiences as volunteers. Through trial and error, and modeling their actions on more experienced supporters they adapted to work as a volunteer. This process is corroborated by the experiential learning theory of Kolb [10]. Specifically, participants in the present study were exposed to providing service to clients and experienced embarrassment and strain as a "concrete experience", and they engaged in "reflective observation", observing the support provided by provider models while reviewing various aspects of their daily experiences. They then engaged in abstract conceptualization by comparing and integrating what they observed to the basics of support and client characteristics that they learned in class. Next, they engaged in "active experimentation" by testing their understanding, and finally they converted their experiences into preferable behavior.

\section{Significance of nursing student volunteers' learning and experience}

The first theme was that nursing student volunteers gained an understanding of the client's diversity and individuality while comparing experiences to what they had already learned in class. This supports previous research [21] asserting that academic inquiry and understanding are further facilitated by relating experiences in daily practices to previous learning in the preliminary stage, which links theory to practice. Based on the characteristics of the fields in which the participants in this study provided services, it was interesting for the second theme- searching for fundamental rules for the care required by clients including the need to avoid risks and ensure safety, and for including the clients' family members within the scope of care. The areas in which the participants volunteered were related to the caring of people with early-onset dementia and their families, and child-rearing mothers, infants, and their families, where psychosocial problems tend to occur. In those environments student volunteers would be most likely to encounter recipients in high-risk situations frequently. 
We believe that these areas allowed the students to gain a deeper understanding of the need to include the clients' family members within the scope of care, based on what they previously learned in nursing class. Regarding the lack of sequentiality of experiencing service provision prior to learning in class programs, since learning is more effectively integrated through both, it appeared that there through reflection on the discussions during the monthly meetings [22] and of the faculty members acting as facilitators [23]. Since it is possible to integrate the experience of providing service in the community and classroom learning, we believe that this type of cyclic learning is useful in helping nursing student volunteers gain a better understanding of the community to ensure more effective contributions.

Understanding the basics of healthcare practices was the second theme. Volunteering led to an understanding of the organization of the basic tenets of nursing care- with observation, communication, and provision of services from the first category; this is in addition to cooperating, both within an organization and with other organizations, and mentioning the importance of continual care, which corresponds with the results of previous research [24]. Even though these concepts are considered to be at an advanced level in the nursing curriculum, considering the current trend of integrating service programs based believe that this is both an appropriate and desirable type of learning.

The third theme consisted of the nursing students envisioning the future: for example, imagining their future career, life and increasing interest in volunteer activities. The effects of experiencing service through volunteering included interest in an area of specialization, socialization into an occupation [26], creating connections between others and themselves, building relationships, as well as increased understanding of social opportunities and increased interest in volunteer activities [27,28], which is consistent with the results of the present research. Imagining themselves at future life stages also leads to the understanding that volunteer work involving assisting others is them to learn desirable behaviors that will lead to the socialization later in life and promotes the smooth transition from one stage of life to the next, which is consistent with previous research [29]. The university years are a transition period of expanding values, attitudes, psychology, society, and moral dimensions [30]. The experience of community service not only help young people mature, but also acts as a bridge that aids in the transition from youth to adulthood, which may result in greater social awareness and development of civic responsibility or civic commitment. Our results appear to support this assertion.

\section{Conclusions and Suggestions for Future Nursing Education}

The results of this study demonstrate the learning gained from and the significance of experiences of nursing university graduate who participated in two different types of health volunteering - providing support to child rearing women and their families and providing support to people with early-onset dementia and their families that included the characteristics of service learning. Through their experience of providing services to the community, the nursing student volunteers developed: an understanding of their clients and of the basics of healthcare practices, and were able to envision their would be no major negative effects because of reinforcement provided in local communities in a variety of forms into nursing classes [25], we a type of preparation for a future they have not yet reached. It allows future better.

Currently, the time and effort required to complete the nursing curriculum, as well as the burden of working to create partnerships between students, faculty, and local community partners are problems that cause hesitation in including service learning in the formal education curriculum. However, the inclusion of service programs, wherein families are considered a single unit, and other elements of service learning and the accumulation of the results of monitoring and investigation through portfolio creation and reflection on learning gained by nursing students can be used as one choice when coordinating and integrating service programs based on the community into curricula in a variety of ways in the future.

\section{Limitations}

This study focused on two types of volunteers who were recruited from among the nursing department graduates of a single university. Thus, the small sample size makes it impossible to generalize the results of this study to the outcomes that can be gained through volunteer activities in all fields. In addition, since the period of volunteer activity ranged from 7 to 36 months, we cannot rule out the possibility of bias due to this wide variation. Therefore, further study with a larger sample of young people engaged in volunteering in different fields during a consistent period of time is required.

\section{Competing Interests}

The authors declares that the they have no competing interests.

\section{Author Contributions}

CK was responsible for the idea that formed the basis for this study and the structure of the study. CK and JM both collected and analyzed the data and prepared the manuscript for publication.

\section{Acknowledgements}

The authors thank all the participants, the representatives and all members of the volunteering association for child rearing women, people with early-onset dementia, and their families.

\section{References}

1. Utsumi S (2014) What is volunteering? From an educational perspective In: Utsumi S, Nakamura $Y$ (Ed) New recommendations on the study of volunteering: What to learn in the field of offering and receiving support Showado Co., Ltd, Japan, pp.2-28.

2. Mitsuhashi $\mathrm{Y}$, Tashiro J, Ozawa M, Hishinuma M, Kawagoe $\mathrm{H}$, et al. (2004) Perceived 'primary health issues and care' and experiences of volunteer activities of nursing students. Journal of St. Luke's Society for Nursing Research 8: 36-43.

3. Beck J, Chretien K, Kind T (2015) Professional identity development through service learning: A qualitative study of first-year medical students volunteering at a Medical Specialty Camp. Clin Pediatr (Phila) 54: 12761282.

4. Saleem F, Hassali MA, Ibrahim ZS, Rasheedy AA, Aljadhey H (2015) Perceptions and attitudes of pharmacy students towards volunteering at health promotional programs: a cross-sectional study from Malaysia. $J$ Community Health 40: 285-290.

5. Sheu LC, Zheng P, Coelho AD, Lin LD, O'Sullivan PS, O'Brien BC, et al. (2011) Learning through service: student perceptions on volunteering at interprofessional hepatitis B student-run clinics. J Cancer Educ 26: 228233.

6. The Central Council for Education (2002) Response to the Central Council for Education: Methods of advancing youth volunteer activities and experience-based activities-Report. 
Citation: Kimura C, Masuya J (2017) Significance of Nursing Students' Experiences as Health Volunteers in Communities: A Qualitative Study. Int J Nurs Clin Pract 4: 232. doi: https://doi.org/10.15344/2394-4978/2017/232

7. Nagamatsu Y, Tashiro J, Hishinuma M, Matsutani M, Oikawa I, et al. (2007) Useful information and supports in the service learning curriculum for the nursing students who work as volunteers overseas. -Experiences of Voluntary activities by Japanese nursing students in Thailand-. Journal of St. Luke's Society for Nursing Research 11: 62-67.

8. Tashiro J, Nagamatsu Y, Omori J, Hishinuma M, Matsutani M, et al. (2007) Development of an e-learning program for the community and supporting student health volunteer: process of the development. Journal of St. Luke's Society for Nursing Research 11: 109-115.

9. Furco A (1996) Service learning: A balanced approach to experiential education. Expanding boundaries: Serving and learning. Washington, DC: Corporation for National Service, USA, pp. 2-6.

10. Kolb DA.(1984) Experimental learning: Experience as the Source of Learning and Development. Prentice Hall, New Jersey, USA, pp. 20-38.

11. Boyd K (2016) The Curriculum of Caring: Fostering Compassionate, Person-Centered Health Care. AMA J Ethics 18: 384-392.

12. Holloway AS (2002) Educational innovations: Service-learning in community college nursing education. J Nurs Educ 41: 440-442.

13. Mayne L, Glasscoff M (2002) Service learning: preparing a health care workforce for the next century. Nurse Educ 27: 191-194.

14. Jacoby B (1996) Service-learning in higher education: Concepts and practices. , Jossey-Bass, San Francisco, USA, pp. 1-25.

15. Kimura C, Sonobe M, Ikeda M (2016) Case study: Childcare volunteering through collaboration among university students, community residents, and the local government - Exploration of organizational development and learning of participants. The Journal of Interprofessional Collaboration in Health and Social Care 9: 2-12.

16. Guba EG, Lincoln YS (1994) Competing paradigms in qualitative research In: Denzin NK, Lincoln YS (Ed) Handbook of qualitative research, Sage, Thousand Oaks, CA, 105-117.

17. Loise W, Colm F, Lynn M, Heather ML (2012) Volunteer management: an exploratory case study within the British Red Cross. Manage Decis 50: 349367.

18. Moreno MA, Furtner F, Rivara FP (2013) Advice for patients. Adolescent volunteering. JAMA Pediatrics 167: 400

19. The Ministry of Education, Culture, Sports, Science and Technology (2011) Study meeting final report about the way of the nursing system talented person education in the university-Report.

20. Davis MH (2005) Becoming (and remaining) a community volunteer: Does personality matter? In: Omoto A (Ed) Processes of community change and social action, Lawrence Erlbaum, Mahwah, New Jersey, USA, pp. 67-82.

21. Williams $R$ (1990) The impact of field education on student development research findings. Journal of Cooperative Education 27: 29-45.

22. Fertman Cl (1994) Four Basic Elements. In: Fertman Cl (Ed) Service learning for all students. Phi Delta Kappa Educational Foundation, Bloomington, , Indiana, USA, pp. 11-18.

23. Elam CL, Musick DW, Sauer MJ, Skelton J (2002) How we are implementing a service- learning elective. Med Teach 24: 249-253.

24. Primavera J (2008) The unintended consequences of volunteerism. J Prev Interv Community 18: 125-140.

25. Callister LC, Hobbins-Garbett D (2000) Enter to learn, go forth to serve": Service learning in nursing education. J Prof Nurs 16: 177-183.

26. Bailey PA, Carpenter DR, Harrington P (2002) Theoretical foundations of service-learning in nursing education. J Nurs Educ 41: 433-436.

27. Flanagan C, Gill S, Gallay L (2005) Social participation and social trust in adolescence: The importance of heterogeneous encounters. In: Omoto A (Ed) Processes of community change and social action, Lawrence Erlbaum, Mahwah, New Jersey, USA, pp. 149-166.

28. Gehrke PM (2008) Civic engagement and nursing education. ANS Adv Nurs Sci 31: 52-66.

29. Ohsaka $\mathrm{H}$ (2010) How volunteering with the elderly prepares individuals for old age: Results of community volunteering activities. Journal of the National Women's Education Center of Japan 14: 112-118.

30. Pascarella ET, Terenzini PT (2005) How College Affects Students A Summary. In: Pascarella ET, Terenzini PT (Ed) How College Affects Students Volume 2 A Third Decade of Research, Jossey-Bass, San Francisco, USA, pp. 571-578. 